\title{
Gender Representation of Emotions in the Novel A Hero of Our Time by Mikhail Lermontov
}

\author{
Abramova Veronika Igorevna ${ }^{1}$ \\ Associate Professor, L.N. Tolstoy Tula State Pedagogical University \\ Tula, Russia
}

(date of receiving: November, 2017; date of acceptance: February, 2018)

\begin{abstract}
The article deals with emotions represented through images of the characters of M.Y. Lermontov's novel A Hero of Our Time. The author consecutively analyzes elements of the text, in which emotions of male and female characters are nominated, directly expressed and described. The number of lexical units and text elements involved in the representation of a particular emotion is recorded in tables. The author found and described in detail representation of the following emotions: joy, sadness, surprise, anger, curiosity, contempt, disgust, shame, guilt, fear. The author comes to the conclusion that an androcentric emotional picture of the world is created in the novel $A$ Hero of Our Time. The male characters represent a wider range of emotions, in greater quantity; use more expressive means in this picture of the world than the female characters. The author explains this by the fact that the writer, who created the novel, as well as the narrator characters in the text, is a man. In addition, representation of emotions is affected by a form of the narration (Pechorin's diary) and a cultural context.
\end{abstract}

Keywords: Emotion, Nomination, Description, Expression, Gender Representation.

1. E-mail: istinijobraz@mail.ru 


\title{
Гендерная репрезентация эмоций в романе М.Ю. Лермонтова «Герой нашего времени»
}

\section{Абрамова Вероника Игоревна ${ }^{1}$}

Доцент, Тульский государственный педагогический университет им. Л.Н.

$$
\text { Толстого, }
$$

Тула, Россия.

(дата получения: ноябрь 2017 г.; дата принятия: февраль 2018 г.)

\begin{abstract}
Аннотация
В статье рассматриваются эмоции, репрезентированные через образы персонажей романа М.Ю. Лермонтова «Герой нашего времени». Автор последовательно анализирует элементы текста, в которых эмоции мужских и женских персонажей номинированы, непосредственно выражены и описаны. Количество лексических единиц и элементов текста, участвующих в репрезентации той или иной эмоции, заносится в таблицы. Автором найдена и подробно описана репрезентация следующих эмоций: радость, печаль, удивление, гнев, любопытство, презрение, отвращение, стыд, чувство вины, страх. Автор приходит к выводу, что в романе «Герой нашего времени» создана андроцентричная эмоциональная картина мира. В ней персонажи-мужчины репрезентируют больший спектр эмоций, в большем количестве, используют больше выразительных средств, чем персонажи-женщины. Автор объясняет это тем, что писатель, создавший произведение, как и герои-нарраторы в тексте, является мужчиной. Кроме того, на репрезентацию эмоций влияет форма повествования (дневник Печорина) и культурный контекст.
\end{abstract}

Ключевые слова: Эмоция, Номинация, Описание, Выражение, Гендерная Репрезентация.

1. E-mail: istinijobraz@mail.ru 


\section{Введение}

Размышляя над проблемой языковой репрезентации эмоций в художественном тексте, В.И. Шаховский выделил следующие случаи: обозначение эмоций, выражение эмоций, описание эмоций. Слова, обозначающие эмоции, выполняют номинативную функцию: «лексика, обозначающая эмоции, эмотивной не является, она - индикативная, логикопредметная», «Эмоция, обозначенная в таких словах, на уровне реализации представляет собой не непосредственное чувство, а лишь логическую мысль о нем» (Шаховский 2012. 93). Ученый отмечает, что лексику, называющую эмоции, можно считать «ассоциативно-эмотивной», поскольку она, «не выражая эмоций, ассоциативно отсылает сознание говорящих к сфере эмоций» (Там же. 94).

Под выражением эмоций В.И. Шаховский понимает «их снятие языком, манифестацию в речи, сопровождаемую внутренним и внешним переживанием» (Там же. 96). На лексическом уровне языка выражение эмоций осуществляется с помощью эмотивной лексики. На синтаксическом уровне используются усилительные структуры. Стилистическими средствами выражения эмоций могут быть повторы эмоциональных усилителей, параллельные конструкции, метафоры. Ученый отмечает, что эмоции удивления, возмущения и радости часто выражаются в восклицательных, в вопросительно-восклицательных предложениях, а эмоции грусти и печали - в повествовательных» (Шаховский 2008. 195).

Описание эмоций В.И. Шаховский называет осознанным их выражением. Ученый выделяет специальные лексические единицы, которые описательно передают эмоциональное состояние. Это наречия и глаголы, описывающие эмоции говорящего; существительные, включающие термины эмоций с предлогом «с»; существительные, обозначающие физиологические проявления эмоций; прилагательные, характеризующие эмоциональное состояние 
(Шаховский 2012. 98). Особое внимание В.И. Шаховский обращает на часто присутствующее в художественной литературе лексическое описание эмоциональных кинем. Наиболее информативным ученый считает лексическое описание эмоциональных кинем лица говорящего, в частности губ и глаз (Там же).

\section{Основная часть}

Герои романа М.Ю. Лермонтова «Герой нашего времени», особенно рефлектирующий, ведущий дневник Печорин, часто размышляют о чувствах. Эти размышления можно разделить по гендерному признаку в зависимости от того, персонаж какого пола упоминает ту или иную эмоцию. Проанализировав текст романа, мы сделали сплошную выборку примеров, включающих номинации эмоций. Результат представлен в таблице (числами показано количество найденных лексических единиц):

\begin{tabular}{|c|c|c|}
\hline Эмоция & М & Ж \\
\hline радость & 6 & 0 \\
\hline печаль / грусть & 5 & 3 \\
\hline отвращение & 1 & 0 \\
\hline бешенство/гнев & 1 & 0 \\
\hline презрение & 1 & 1 \\
\hline стыд/смущение & 0 & 2 \\
\hline страх & 3 & \\
\hline
\end{tabular}

Номинации эмоций присутствуют в речи одного мужского (Печорин) и двух женских персонажей (Вера, княгиня Лиговская).

Рассмотрим сначала высказывания-размышления Печорина. В них фигурируют номинации эмоций «радость» и «печаль/грусть»: «к печали я так 
же легко привыкаю, как к наслаждению» (здесь и далее курсив наш - В.А.); «всякое напоминание о минувшей печали или радости болезненно ударяет в мою душу и извлекает из нее все те же звуки...»; «Может быть, - подумал я, ты оттого-то именно меня и любила: радости забываются, а печали никогда...»; «грусть в обществе смешна, а слишком большая веселость неприлична...»; «Быть для кого-нибудь причиною страданий и радостей, не имея на то никакого положительного права, - не самая ли это сладкая пища нашей гордости?»; «Моя любовь никому не принесла счастья, потому что я ничем не жертвовал для тех, кого любил: я любил для себя, для собственного удовольствия: я только удовлетворял странную потребность сердца, с жадностью поглощая их чувства, их радости и страданья - и никогда не мог насытиться»; «...отчего я не хотел ступить на этот путь, открытый мне судьбою, где меня ожидали тихие радости и спокойствие душевное?..»; «Я вернулся домой, волнуемый двумя различными чувствами. Первое было грусть».

Печорин номинирует эмоцию «отвращение»: «Когда я был еще ребенком, одна старуха гадала про меня моей матери; она предсказала мне смерть от злой жены; это меня тогда глубоко поразило; в душе моей родилось непреодолимое отвращение к женитьбе...».

В комментарии, который дает своей реплике Печорин, номинирована эмоция «бешенство»: «Я буду иметь честь прислать к вам нониче моего секунданта, - прибавил я, раскланявшись очень вежливо и показывая вид, будто не обращаю внимания на его бешенство».

В речи Печорина номинирована эмоция «презрение»: «Я до сих пор стараюсь объяснить себе, какого роду чувство кипело тогда в груди моей: то было и досада оскорбленного самолюбия, и презрение, и злоба...».

В размышлениях Печорина номинирована эмоция «страх»: «...возбуждать к себе чувство любви, преданности и страха - не есть ли первый признак и 
величайшее торжество власти?»; «А! господин Грушницкий! ваша мистификация вам не удастся... мы поменяемся ролями: теперь мне придется отыскивать на вашем бледном лице признаки тайного страха»; «А мы, их жалкие потомки, скитающиеся по земле без убеждений и гордости, без наслаждения и страха, кроме той невольной боязни, сжимающей сердце при мысли о неизбежном конце, мы не способны более к великим жертвам ни для блага человечества, ни даже для собственного счастия».

Обратимся теперь к номинациям эмоций, которые мы встречаем в речи женских персонажей. Женщины номинируют только две эмоции: «радость» и «печаль». Одно из высказываний-размышлений о печали и радости принадлежит Вере: «...ты любил меня как собственность, как источник радостей, тревог и печалей, сменявшихся взаимно, без которых жизнь скучна и однообразна». Печаль также номинируется в реплике княгини Лиговской, которая говорит о своей дочери Мери: «Но она больна, и я уверена, что это не простая болезнь! Печаль тайная ее убивает...».

Теперь рассмотрим выражение эмоций персонажами романа (в таблице учитывается количество реплик):

\begin{tabular}{|c|c|c|}
\hline Эмоция & М & Ж \\
\hline радость & 9 & 0 \\
\hline печаль & 1 & 0 \\
\hline удивление & 1 & 0 \\
\hline гнев & 1 & 0 \\
\hline презрение & 1 & 1 \\
\hline стыд/смущение & 0 & 0 \\
\hline любопытство/интерес & 1 & 0 \\
\hline чувство вины & 1 & 2 \\
\hline страх & 2 & \\
\hline
\end{tabular}


Эмоции в романе выражают шесть мужских (странствующий офицер, Максим Максимыч, слепой, Печорин, Грушницкий, казак) и три женских (Бэла, ундина, княжна Мери) персонажа. Кроме того, выражена эмоция группы лиц - трех офицеров.

Сначала рассмотрим выражение эмоций персонажами-мужчинами.

Радость у мужских персонажей выражена с помощью вопросительных и восклицательных предложений с соответствующим комментарием, в котором отмечаются просодическое оформление фраз и жесты говорящего: «Выздоровела? - спросил я у штабс-капитана, схватив его за руку и невольно обрадовавшись» (CO); «Завязка есть! - закричал я в восхищении, - об развязке этой комедии мы похлопочем. Явно судьба заботится о том, чтоб мне не было скучно»; «А-га! - подумал я, - вы не на шутку сердитесь, милая княжна; погодите, то ли еще будет!» (П). Кроме того, используются стилистические повторы: «Толкуйте, толкуйте, доктор! вы мне не помешаете радоваться. Он не знает, - прибавил Грушницкий мне на ухо, - сколько надежд придали мне эти эполетьл... О, эполеть, эполеть! ваши звездочки, путеводительные звездочки... Нет! я теперь совершенно счастлив» (Г); синонимические накопления (в данном случае синонимы контекстуальные): «Видишь, я прав, сказал опять слепой, ударив в ладоши, - Янко не боится ни моря, ни ветров, ни тумана, ни береговых сторожей; это не вода плещет, меня не обманешь, - это его длинные весла»; эмоциональные интенсификаторы в сочетании с сегментированными конструкциями: «Что ты? что ты? Печорин?.. Ах, Боже мой!.. да не служил ли он на Кавказе?.. - воскликнул Максим Максимыч, дернув меня за рукав»; «Боже мой, боже мой! да куда это так спешите?.. Мне столько бы хотелось вам сказать... столько расспросить... Ну что? в отставке?.. как?.. что поделывали?..»; «Ну так!.. так!.. Григорий Александрович?.. Так ведь его зовут?.. Мы с твоим барином были приятели, - прибавил он, ударив дружески по плечу лакея, так что заставил его пошатнуться» (MM); разрыв 
синтаксического целого (дислокация): «А... ты?.. а вы? - пробормотал со слезами на глазах старик... - сколько лет... сколько дней... да куда это?..» (MМ). В высказываниях Максима Максимыча используется графическое оформление в виде многоточий.

Печаль выражается с помощью вопросительных и восклицательных предложений, неполных конструкций, повторов, снова используется графическое оформление: «Неужто сейчас?.. Да подождите, дражайший!.. Неужто сейчас расстанемся?.. Столько времени не видались...» (МM).

Мужское удивление выражено с помощью восклицательного предложения, эмоционального интенсификатора (частицы -ка), инверсии: «Что за диво! Скажите-ка, пожалуйста, - продолжал штабс-капитан, обращаясь ко мне, - вы вот, кажется, бывали в столице, и недавно: неужели тамошная молодежь вся такова?» (MM).

Мужской гнев выражен с помощью восклицательного предложения и эмоциональных интенсификаторов: «Веди меня куда-нибудь, разбойник! хоть к черту, только к месту!»- закричал я (П).

Мужское презрение выражено с помощью восклицательного предложения, эмоционального интенсификатора, в качестве которого в данном случае используется слово «матерьялист», выделения этого слова в речевом потоке: «Ты во всем видишь худую сторону... матерьялист! - прибавил он презрительно» (Г).

Мужское любопытство выражено с помощью вопросительного предложения и использования эмоционального интенсификатора: «А, чай, много с вами бывало приключений? - сказал я, подстрекаемый любопытством» (CO).

Мужское чувство вины выражено с помощью эмоционального интенсификатора и вводной восклицательной конструкции: «Никогда себе не прощу одного: черт меня дернул, приехав в крепость, пересказать Григорью 
Александровичу все, что я слышал, сидя за забором; он посмеялся, - такой хитрый! - а сам задумал кое-что» (ММ).

Мужской страх выражен с помощью восклицательных и вопросительных предложений с соответствующим комментарием: «Меня в дверях встретил казак мой с испуганным лицом. - Плохо, ваше благородие! - сказал он мне»; «"Знаешь, что случилось?" - сказали мне в один голос три офицера, пришедшие за мною; они были бледны как смерть».

Теперь перейдем к рассмотрению выражения эмоций женскими персонажами. Спектр выраженных женских эмоций гораздо уже, чем спектр мужских. В книге Е.В. Лаврентьевой «Повседневная жизнь дворянства пушкинской поры» читаем: «Женщина хорошего тона, “чтобы с честью поддерживать свою репутацию, должна была казаться спокойной, ровной, бесстрастной, не выказывать ни особого внимания, ни повышенного любопытства, должна была владеть собою в совершенстве”» (Лаврентьева 2007).

Женская печаль выражается с помощью синонимических накоплений, градации: «Я вчера целый день думала, - отвечала она сквозь слезы, придумыввала разные несчастья: то казалось мне, что его ранил дикий кабан, то чеченец утащил в горы... А нынче мне уж кажется, что он меня не любит» (Б); повествовательного и восклицательного предложений с соответствующими комментариями: «Туман густеет, - возразил опять женский голос с выражением печали» (У); «О нет! - и лицо ее стало так задумчиво, так грустно...» (M).

Женское смущение выражено с помощью вопросительного предложения с соответствующим комментарием: «она немножко покраснела и быстро проговорила: - Не правда ли, мсье Печорин, что серая шинель гораздо больше идет к мсье Грушницкому?..» (М).

Женский страх выражен с помощью восклицательного предложения, 
эмоционального интенсификатора, неполной конструкции, графического оформления: «Mon Dieu, un Circassien!.. - вскрикнула княжна в ужасе»; с помощью вопросительного предложения с соответствующим комментарием: «Что вам угодно? - произнесла она дрожащим голосом, бросая кругом умоляющий взгляд» (M).

Перейдем к описанию эмоций. В таблице учтены не только отдельные лексические единицы, но и словосочетания и фразеологизмы, участвующие в дескрипции эмоций.

\begin{tabular}{|c|c|c|}
\hline Эмоция & М & Ж \\
\hline радость & 14 & 1 \\
\hline печаль / грусть & 11 & 2 \\
\hline удивление & 7 & 1 \\
\hline гнев & 4 & 4 \\
\hline презрение & 7 & 3 \\
\hline стыд/смущение & 3 & 1 \\
\hline любопытство/интерес & 2 & 0 \\
\hline чувство вины & 2 & 5 \\
\hline страх & 9 & \\
\hline
\end{tabular}

В романе описаны эмоции восьми мужских (Печорин, Максим Максимыч, странствующий офицер, Грушницкий, слепой, казак, Вернер, драгунский капитан) и пяти женских персонажей (Бэла, ундина, Вера, княжна Мери, княгиня Лиговская). Кроме того, в нескольких случаях описаны эмоции группы лиц: два раза мужской (драгунский офицер и его товарищи; три офицера), один раз женской (барышни).

Мужская радость репрезентирована с помощью лексики: «Очень рад» (странствующий офицер о себе); «Хорошо вам радоваться...» (Максим 
Максимыч о странствующем офицере); «вы мне не помешаете радоваться» (Г); «...мне делается или слишком грустно, или слишком весело. То и другое утомительно, когда нет положительной причины грустить или радоваться» (П); «я теперь совершенно счастлив» (Г); в описании используется кинема глаз: «У него в глазах сверкала радость» (ММ); мимический компонент: «Он просиял, как солнце...» (Г); такесический знак: «Пришел Грушницкий и бросился мне на шею: он произведен в офицеры». Непосредственное выражение эмоций сопровождается следующими описаниями: «спросил я у штабс-капитана, схватив его за руку и невольно обрадовавиись» (CO), «воскликнул Максим Максимыч, дернув меня за рукав», «прибавил он, ударив дружески по плечу лакея, так что заставил его пошатнуться» (MМ), «пробормотал со слезами на глазах старик» (ММ), «сказал опять слепой, ударив в ладоши», «закричал я в восхищении» (П). Эмоция сопровождается такесическими знаками («схватив его за руку», «дернув меня за рукав», «ударив дружески по плечу»), жестами (ударив в ладоши), кинесикой (со слезами на глазах), просодикой (воскликнул, пробормотал, закричал).

Мужская печаль описана с помощью лексики: «мне делается... слишком грустно» (П); «мне так, право, грустно, как вспомню» (ММ); «мне становилось грустно, когда слушал ее из соседней комнаты» (MМ); «Еще, признаться, меня вот что печалит: она перед смертью ни разу не вспомнила обо мне...» (MМ); «явно было, что старика огорчало небрежение Печорина» (MМ); «Когда он ушел, то ужасная грусть стеснила мое сердце» (П); «Я шел медленно; мне было грустно» (П); «У Грушницкого растрепанная прическа и отчаянный вид; он, кажется, в самом деле огорчен, особенно самолюбие его оскорблено»; просодических компонентов: «слепой мальчик точно плакал, долго, долго»; «Я молился, проклинал, плакал, смеялся... нет, ничто не выразит моего беспокойства, отчаяния!..» (П); синонимических накоплений: «И долго я лежал неподвижно и плакал горько, не стараясь удерживать слез и рыданий; я 
думал, грудь моя разорвется; вся моя твердость, все мое хладнокровие исчезли как дым» (П).

Мужское удивление описано в романе с помощью лексики: «Это обстоятельство меня удивило»; «Меня невольно поразила способность русского человека применяться к обычаям тех народов, среди которых ему случается жить»; «воскликнул я с видом любопьтства, подливая ему чая» (CO); «Он посмотрел на меня с удивлением, проворчал что-то сквозь зубы и начал рыться в чемодане» (МM); «Казак мой был очень удивлен, когда, проснувшись, увидел меня совсем одетого»; «...кажется, княжна отвечала на его мудрые фразы довольно рассеянно и неудачно, хотя старалась показать, что слушает его со вниманием, потому что он иногда смотрел на нее $c$ удивлением» (Г); «Он посмотрел на меня с удивлением» (В).

Мужской гнев описан с помощью лексики: «Я приехал в довольно миролюбивом расположении духа, но все это начинало меня бесить» (П); метафоры: «Неизъяснимое бешенство закипело в груди моей» (П); кинесики и проксематического знака: «Он на меня бросил бешеный взгляд, топнул ногою $u$ отошел прочь» (Г); мимического компонента: «ОН пожелтел, посинел; скрытая злоба изобразилась на лице его» (драгунский капитан).

Мужское чувство презрения описано с помощью лексики: «Душа обессилела, рассудок замолк, и если б в эту минуту кто-нибудь меня увидел, он бы с презрением отвернулся» (П); «Что для меня Россия! - отвечал ее кавалер, - страна, где тысячи людей, потому что они богаче меня, будут смотреть на меня с презрением...»; «я себя презираю, а вас ненавижу» (Г); жестового компонента: «...вот он вынул одну тетрадку и бросил ее $c$ презрением на землю...» (ММ); используется стилистический повтор: «Я иногда себя презираю... не оттого ли я презираю и других?..» (П).

Представление о мужском чувстве презрения описательно (с помощью лексики) представлено в признании Веры: «...я не вынесла этого испытания, 
мое слабое сердце покорилось снова знакомому голосу... ты не будешь презирать меня за это, не правда ли?» и в реплике княжны Мери: «Или вы меня презираете, или очень любите! - сказала она наконец голосом, в котором были слезы. - Вы меня не презираете, не правда ли?». В высказывании княжны Мери используется стилистический повтор, усиливающий эмоцию. И та, и другая фразы обращены к Печорину.

Мужской стыд описан с помощью лексики: «удалился к своим пристыженнылм товарищам, которые тотчас увели его в другую комнату» (группа мужчин во главе с драгунским офицером); «Он смутился и задумался: ему хотелось похвастаться, солгать - и было совестно, а вместе с этим было cтыљдно признаться в истине»; мимического компонента: «Он покраснел; ему было стыдно убить человека безоружного...» (Г).

Мужское любопытство описано с помощью лексики и эмоционального интенсификатора: «Мне страх хотелось вытянуть из него какую-нибудь историйку - желание, свойственное всем путешествующим и записывающим людям»; «сказал я, подстрекаемыий любопытством» (СО).

Чувство вины у мужчин описано с помощью лексики: «Я был в духе, импровизировал разные необыкновенные истории; княжна сидела против меня и слушала мой вздор с таким глубоким, напряженным, даже нежным вниманием, что мне стало совестно» (П); просодики и кинесики: «Штабскапитан после некоторого молчания продолжал, топнув ногою о землю: Никогда себе не прощу одного...» (MМ).

Мужской страх представлен в описании с помощью лексики: «такая печальная, что я испугался» (ММ); «Признаюсь, я испугался, хотя мой собеседник очень был занят своим завтраком: он мог услышать вещи для себя довольно неприятные, если б неравно Грушницкий отгадал истину...»; «я взглянул на нее и испугался» (П); фразеологии: «У меня мороз пробежал по коже от этого смеха...» (ММ); кинесики: «Он не отвечал и с ужасом 
отвернулся» (В); мимического компонента: «Меня в дверях встретил казак мой с испуганным лицом»; «они были бледны, как смерть» (три офицера); отмечается физиологическое проявление эмоции: «я содрогнулся, подумав, что часто здесь, в глухую ночь, по этой дороге, где две повозки не могут разъехаться, какой-нибудь курьер раз десять в год проезжает, не вылезая из своего тряского экипажа» (СО); используются восклицательные предложения: «О, тут ужасное подозрение закралось мне в душу, кровь хльнула мне в голову!. Оглядываюсь - мы от берега около пятидесяти сажен, а я не умею плавать!».

Перейдем к описаниям женских эмоций в романе.

Женская радость описана с помощью лексики: «Она казалась удивлена и обрадована» (M).

Женская печаль репрезентирована в описании более разнообразно: с помощью лексики: «если ты снова будешь грустить, то я умру»; «походит, да и придет; а если ты будешь грустить, то скорей ему наскучишь»; «все грустила, напевала свои песни вполголоса»; «она дня два поплакала, а потом забыла»; «Она заплакала»; «отвечала ... сквозь слезы»; мимического компонента и эмоционального интенсификатора: «сидела на кровати в черном шелковом бешмете, бледненькая, такая печальная, что я испугался» (Б); «Вера все это заметила: на ее болезненном лище изображалась глубокая грусть...»; «лицо ее стало так задумчиво, так грустно»; «лицо выражало глубокое отчаянье, на глазах сверкали слезы» (В); жестового компонента и кинесики: «упала на постель и закрыла лицо руками» (Б); «Она подняла на меня томный, глубокий взор и покачала головой; ее губы хотели проговорить что-то - и не могли; глаза наполнились слезами; она опустилась в кресла и закрыла лицо руками»; «...пред нею на столике была раскрыта книга, но глаза ее, неподвижные и полные неизъяснимой грусти, казалось, в сотый раз пробегали 
одну и ту же страницу, тогда как мысли ее были далеко...» (М); просодики: «возразил опять женский голос с выражением печали» (У); просодики и кинесики: «Мы долго молчали; ее большие глаза, исполненные неизъяснимой грусти, казалось, искали в моих что-нибудь похожее на надежду...» (М).

Женское удивление описано с помощью лексики: «Она казалась удивлена и обрадована» (М); «Она была удивлена, когда на вопрос ее: имею ли я ей сказать что-нибудь особенно важное? - я отвечал, что желаю ей быть счастливой и прочее» (КЛ).

Женский гнев описывает Печорин, говоря о княжне Мери: «...за это я был вознагражден взглядом, где блистало самое восхитительное бешенство» (используется кинема глаз).

Женское презрение описывают мужские персонажи. Печорин говорит о княжне Мери: «Куда девалась ее живость, ее кокетство, ее капризы, ее дерзкая мина, презрительная ульбка, рассеянный взгляд?..» (используется мимический компонент, кинема губ). Ее же характеризует Вернер: «княжна смотрит на них [молодых людей] с некоторым презрением: московская привычка!» (используется кинема глаз). Нами также отмечен случай, когда эмоция «презрение» предписывается мужским персонажем женскому. Печорин Мери: «Княжна, - сказал я, - вы знаете, что я над вами смеялся?.. Вы должны презирать меня».

Женские персонажи тоже описывают эмоцию «презрение». Вера признается Печорину: «Любившая раз тебя не может смотреть без некоторого презрения на прочих мужчин...».

Женское смущение описано с помощью лексики: «Она смутилась, - но отчего? от своей ошибки или оттого, что мой ответ ей показался дерзким?»; мимического компонента и характеристики темпа речи: «она немножко покраснела и быстро проговорила» (M); эмоционального интенсификатора: 
«Легче птички она к нему подскочила, нагнулась, подняла стакан и подала ему с телодвижением, исполненным невыразимой прелести; потом ужасно покраснела, оглянулась на галерею и, убедившись, что ее маменька ничего не видала, кажется, тотчас же успокоилась» (М).

Женское любопытство репрезентировано с помощью кинемы глаз: «Хорошенькая княжна обернулась и подарила оратора долгим любопьтнным взором» (M).

Женский страх описан с помощью лексики: «Сперва это ее забавляло, а потом испугало»; просодики и кинесики: «вскрикнула княжна в ужасе»; «произнесла она дрожащчим голосом, бросая кругом умоляющщй взгляд» (М); «крутизна обрыва, у которого она стояла, ее не пугала, тогда как другие барышни пищали и закрывали глаза»; описания физиологического проявления эмоции: «Я видел, что она готова уnасть в обморок от страху и негодования».

Сводная таблица, в которой учтены все формы репрезентации эмоций (номинация, выражение, описание), выглядит следующим образом:

\begin{tabular}{|c|c|c|}
\hline Эмоция & М & Ж \\
\hline радость & 29 & 1 \\
\hline печаль / грусть & 17 & 20 \\
\hline удивление & 8 & 2 \\
\hline отвращение & 1 & 0 \\
\hline гнев & 6 & 1 \\
\hline презрение & 9 & 4 \\
\hline стыд/смущение & 3 & 1 \\
\hline любопытство/интерес & 3 & 0 \\
\hline чувство вины & 3 & 9 \\
\hline страх & 14 & \\
\hline
\end{tabular}




\section{Заключение}

Вопреки распространенному гендерному стереотипу о том, что женщины более эмоциональны, чем мужчины, в романе «Герой нашего времени» создается иная эмоциональная картина.

Мужчины испытывают больший спектр эмоций и во многих случаях большее количество раз. Средства репрезентации эмоций мужских персонажей более разнообразны и в количественном плане превышают средства репрезентации эмоций женских персонажей. Небольшой количественный «перевес» в пользу репрезентации эмоций женских персонажей наблюдаем только при использовании эмоциональных кинем, мимических и жестовых компонентов. С учетом того, что женских персонажей меньше, чем мужских, этот «перевес» приобретает особую значимость. Мужские персонажи стремятся выразить эмоцию вербально, женские - невербально.

Андроцентричность эмоциональной картины мира, созданной в романе, мы можем объяснить, во-первых, тем, что оба героя-нарратора (странствующий офицер в первых двух частях и Печорин в последующих трех) являются мужчинами, на первый план, естественно, выходят принадлежащие им эмоции. Во-вторых, один из героев-нарраторов - Печорин - ведет дневник, сама форма которого располагает к «повышенной» репрезентативности эмоций. В-третьих, женских персонажей, эмоции которых репрезентированы в романе, меньше, чем мужских. Этот факт нельзя не учитывать при подсчетах. В-четвертых, нельзя не учитывать культурный контекст. Три из пяти женских персонажей, действующих в романе, - представительницы светского общества. Правила этикета заставляют их сдерживать проявление эмоций. Из мужских персонажей с правилами поведения в светском обществе знакомы далеко не все, поэтому мужчины чувствуют себя более свободно в эмоциональном плане. 
«Женская» часть таблицы отчасти соответствует современному европейскому гендерному стереотипу, согласно которому для женщин более характерны такие эмоции, как «радость», «печаль» и «страх».

В «мужской» части таблицы наблюдаем отступление от современного европейского гендерного стереотипа, согласно которому от мужчин ожидается проявление таких эмоций, как «гнев» и «презрение». Мужчины в романе М.Ю. Лермонтова неожиданно много радуются. Второй по интенсивности проявления является эмоция «печаль», третьей - «страх». Эти эмоции современный европейский гендерный стереотип предписывает женщинам.

Итак, гендерная репрезентация эмоций в романе М.Ю. Лермонтова «Герой нашего времени» зависит от многих факторов: 1) пол автора и героевнарраторов; 2) форма повествования (повествование от первого лица, дневник); 3) историко-культурный контекст, культурная ситуация, описанная в произведении.

\section{Литература}

1- Лаврентьева Е. Повседневная жизнь дворянства пушкинской поры. URL: https://www.booksite.ru/fulltext/lav/ren/tie/va/7.htm (дата обращения 30.10.17).

2- Лермонтов М.Ю. Герой намего времени. URL: http://ilibrary.ru/text/12/index.html (дата обращения 13.10.16).

3- Шаховский В.И. (2008) Лингвистическая теория эмоций. Москва. Изд-во Гнозис.

4- Шаховский В.И. (2012) Категоризация эмоций в лексико-семантической системе языка. Москва. Книжный дом «ЛИБРОКОМ».

\section{Bibliography}

1- Lavrent'eva E. Povsednevnaja zhizn' dvorjanstva pushkinskoj pory. URL: https://www.booksite.ru/fulltext/lav/ren/tie/va/7.htm (data obrashhenija 30.10.17). 
2- Lermontov M.Ju. Geroj nashego vremeni. URL: http://ilibrary.ru/text/12/index.html (data obrashhenija 13.10.16).

3- Shahovskij V.I. (2008) Lingvisticheskaja teorija jemocij. Moskva. Izd-vo Gnozis.

4- Shahovskij V.I. (2012) Kategorizacija jemocij v leksiko-semanticheskoj sisteme jazyka. Moskva. Knizhnyj dom «LIBROKOM».

HOW TO CITE THIS ARTICLE

Veronika Igorevna Abramova (2018). Gender Representation of Emotions in the Novel A Hero of Our Time by Mikhail Lermontov, Issledovatel'skiy Zhurnal Russkogo Yazyka i Literatury, 11(1): pp: 81-99.

DOI: $10.29252 /$ iarll.11.81

URL: http://journaliarll.ir/article-1-134-en.html

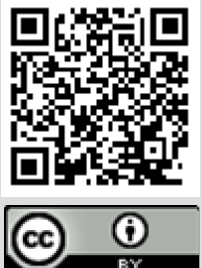




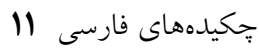

بررسى رابطةٔ احساسات و جنسيت در رمان ((قهرمان عصر ما) ميخائيل لرمانتف

$$
\begin{aligned}
& \text { ورانيكا ايخورونا آبرامووا' } \\
& \text { دانشيار دانشگاه دولتى تربيتمعلم لف تالستوى تولا، }
\end{aligned}
$$

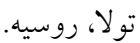

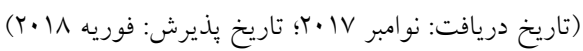

در مقاله حاضر به بررسى احساسات و عواطف نشان دادهده در شخصيت قهرمانان رمـان (اقهرمان عصر ما) م.يو. لرمانتف يرداخته مى شود. مؤلف به بررسى و تحليل بخش هائى از مـتن

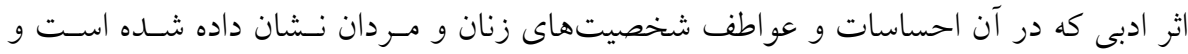
توصيف شده است مى يردازد. مثالها و مصداقهاى موضـوع مـورد بررسى در ايـن مقالـه بــهـ

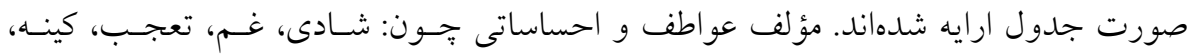
كنجكاوى، نفرت، شرم، حس گناه و ترس را مورد بررسى قرار مى دهد. مؤلف بــه ايـن نتيجـهـ

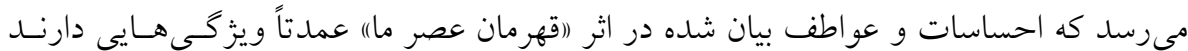

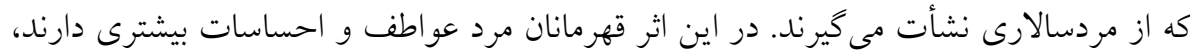

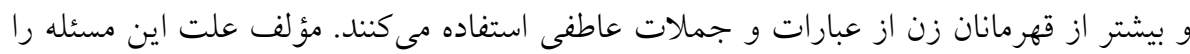

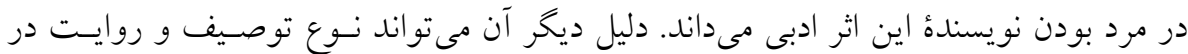
اثر ادبى باشد كه در دفتر خاطرات بيجيجورين وجود دارد.

وازگًان كليدى: احساسات و عواطف، اسم، توصيف، بيان، نمود جنسيتى. 